\title{
Composition and optical properties of silicon oxynitride films deposited by electron cyclotron resonance
}

\author{
A. del Prado ${ }^{\text {a,* }}$, E. San Andrés ${ }^{\mathrm{a}}$, F.L. Martínez ${ }^{\mathrm{a}}$, I. Mártil ${ }^{\mathrm{a}}$, G. González-Díaz ${ }^{\mathrm{a}}$, \\ W. Bohne ${ }^{\mathrm{b}}$, J. Röhrich $^{\mathrm{b}}$, B. Selle ${ }^{\mathrm{b}}, \mathrm{M}$. Fernández ${ }^{\mathrm{c}}$ \\ ${ }^{a}$ Dpto. Física Aplicada III, Facultad Ciencias Fisicas, Universidad Complutense de Madrid, Madrid, 28040, Spain \\ ${ }^{\mathrm{b}}$ Abt. Silizium-Photovoltaik und Ionenstrahl-Labor, Hahn-Meitner-Institut, Berlin, Germany \\ ${ }^{\mathrm{c}}$ Instituto de Ciencia de Materiales, Cantoblanco, 28049, Spain
}

\begin{abstract}
Silicon oxynitride films covering the whole composition range from silicon nitride to silicon oxide have been deposited by electron cyclotron resonance chemical vapor deposition from $\mathrm{SiH}_{4}, \mathrm{O}_{2}$ and $\mathrm{N}_{2}$ gas mixtures. The composition of the films has been determined by heavy-ion elastic recoil detection analysis (HI-ERDA), providing absolute concentrations of all elements, including $\mathrm{H}$, and by Auger electron spectroscopy. Additionally, Fourier transform infrared (FTIR) spectroscopy and ellipsometry measurements have been performed on the same samples for optical characterization.

The concentration of the different species $(\mathrm{Si}, \mathrm{O}, \mathrm{N}$ and $\mathrm{H}$ ) and the density of the films have been calculated and compared to the theoretical values for stoichiometric films. The presence of $\mathrm{N}-\mathrm{H}$ bonds and non-bonded $\mathrm{H}$ results in a significant decrease of the Si concentration with respect to the theoretical value, especially for samples close to silicon nitride composition. The decrease of the $\mathrm{Si}$ concentration results in a decrease of both the $\mathrm{N}$ and $\mathrm{O}$ concentrations. The overall result is a decrease of the density and therefore a decrease of the refractive index with respect to stoichiometric films.

The total $\mathrm{H}$ content determined by ERDA has been compared with the area of the FTIR N-H stretching band, which is frequently used to obtain the $\mathrm{H}$ content. It has been found that the calibration factor for this band depends on composition, increasing with increasing the O content. (C) 2002 Elsevier Science Ltd. All rights reserved.
\end{abstract}

Keywords: Silicon oxynitride; HI-ERDA; ECR

\section{Introduction}

Silicon oxynitride is a very promising material for both electrical and optical applications. The interest arises from the possibility to change the

\footnotetext{
*Corresponding author. Tel.: + 34-91-394-44-34; fax: + 3491-394-51-96.

E-mail address: alvarop@fis.ucm.es (A. del Prado).
}

film properties between silicon oxide and silicon nitride as the composition changes $[1,2]$.

Among all the possible deposition techniques, the electron cyclotron resonance (ECR) plasma method meets the ultra large scale integration (ULSI) low-thermal budget requirement and reduces ion bombardment during deposition, becoming a very promising technique for ULSI technology [3]. 
Silicon oxynitride films deposited by plasma enhanced techniques are known to contain hydrogen, coming from the precursor gases, such as $\mathrm{SiH}_{4}$. The presence of $\mathrm{H}$ and deviations from stoichiometric density have been shown to influence film properties such as their refractive index [4].

The aim of this paper is to study the role of such $\mathrm{H}$ in detail. Based on composition and density measurements, a model is derived to describe the influence of $\mathrm{H}$. The predictions of this model are well in accordance with the experimental data.

\section{Experiment}

Silicon oxynitride films were deposited from $\mathrm{SiH}_{4}, \mathrm{~N}_{2}$ and $\mathrm{O}_{2}$ gas mixtures, using the ECRPECVD technique. Details on the deposition system are given elsewhere [5]. All films were deposited on high-resistivity silicon substrates, intended for optical characterization. All depositions were performed at room temperature.

For this experiment, total gas flow was set to $10.52 \mathrm{sccm}$ (standard cubic centimeter per minute) for a deposition pressure of 0.9 mbar. The $\mathrm{SiH}_{4}$ flow was set to $1.76 \mathrm{sccm}$, while the relative flow of $\mathrm{N}_{2}$ and $\mathrm{O}_{2}$ was changed in order to obtain sample compositions ranging from silicon nitride to silicon oxide.

The composition of the samples was measured using the heavy-ion elastic recoil detection analysis (HI-ERDA) technique. Samples were irradiated with $150 \mathrm{MeV}{ }^{86} \mathrm{Kr}$ ion beams, and the recoiled species were identified by the time-of-flight (ToF) mass separation technique. Details on the setup for the HI-ERDA experiment are given elsewhere [6,7]. The HI-ERDA technique allows for the determination of the absolute content of all the different atoms present in the film, including hydrogen, without need for any reference sample. The uncertainty of the measurements is of the order of $3 \%$. Furthermore, the atomic area density (given in atoms $/ \mathrm{cm}^{2}$ ) of the films is obtained, within an error below $10 \%$.

A different set of samples, deposited under the same conditions was characterized by Auger electron spectroscopy (AES) and the results are compared to the HI-ERDA measurements, in order to check the observed trends.

All samples were characterized by FTIR spectroscopy to obtain information concerning the different bonds present in the films. Additionally, ellipsometry measurements using PLASMOS E2302 equipment operating at the $\mathrm{He}-\mathrm{Ne}$ laser wavelength $(632.8 \mathrm{~nm})$ were performed to obtain the thickness and the refractive index of the films. Incidence and outlet angles both were $70^{\circ}$.

The volume density (atoms $/ \mathrm{cm}^{3}$ ) of the different species, $\mathrm{Si}, \mathrm{N}, \mathrm{O}$ and $\mathrm{H}$ was determined from the HI-ERDA measurements and the ellipsometric thickness and compared to the calculated density of stoichiometric films.

\section{Results and discussion}

The FTIR results for samples deposited under the same conditions have been reported in previous studies $[8,9]$. The spectra show a single dominant band associated to the stretching vibration of the $\mathrm{Si}-\mathrm{O}$ and $\mathrm{Si}-\mathrm{N}$ bonds. This band shifts from around $860 \mathrm{~cm}^{-1}$ for silicon nitride samples to $1070 \mathrm{~cm}^{-1}$ for silicon oxide. This behavior is characteristic of single-phase homogeneous silicon oxynitride and is explained assuming the random bonding model and taking into account the vibration frequencies of the five possible tetrahedra $\mathrm{SiO}_{j} \mathrm{~N}_{4-j}$, with the index $j$ ranging from 0 to 4 [10].

Additionally, the $\mathrm{N}-\mathrm{H}$ stretching band (which shifts from $3330 \mathrm{~cm}^{-1}$ for silicon nitride to $3385 \mathrm{~cm}^{-1}$ for silicon oxide) and the $\mathrm{N}-\mathrm{H}$ bending band (around $1180 \mathrm{~cm}^{-1}$ ) are observed. Since neither $\mathrm{Si}-\mathrm{H}$ nor any $\mathrm{O}-\mathrm{H}$ bands could be observed it is concluded that the $\mathrm{H}$ present in our samples is found mainly in the form of $\mathrm{N}-\mathrm{H}$ bonds. It is also possible for the hydrogen to be present in the films in a non-bonded state, e.g. trapped in microvoids, which is not IR active. Evidence for the presence of such non-bonded hydrogen has been reported for silicon nitride [11].

Stoichiometric films are assumed to have no $\mathrm{H}$ and the only possible bonds are $\mathrm{Si}-\mathrm{N}$ and $\mathrm{Si}-\mathrm{O}$. So, for silicon oxynitride given by the formula $\mathrm{SiO}_{x} \mathrm{~N}_{y} \mathrm{H}_{z}$, stoichiometric films are characterized 
by $z=0$ and the following relationship [12]:

$2 x+3 y=4$.

The incorporation of $\mathrm{H}$ into the films results in a deviation from the stoichiometric composition. In order to quantify this deviation, the concentrations of all the constituents of silicon oxynitride ( $\mathrm{Si}, \mathrm{N}, \mathrm{O}$ and $\mathrm{H}$ ) have been measured and compared to the stoichiometric values. Based on the results, a theoretical model to describe the influence of $\mathrm{H}$ in composition and density has been developed. The model is explained in detail in the following discussion.

According to the FTIR measurements, a negligible concentration of $\mathrm{Si}-\mathrm{H}$ bonds will be assumed. Furthermore, from the HI-ERDA measurements, a linear correlation between the $\mathrm{H}$ and the $\mathrm{N}$ concentrations has been found

$[\mathrm{H}]=X_{\mathrm{H}} \mathrm{N}$

with $X_{\mathrm{H}}=0.300 \pm 0.009$. This value includes both $\mathrm{H}$ incorporated in the form of $\mathrm{N}-\mathrm{H}$ bonds and non-bonded $\mathrm{H}$. According to this result, the $\mathrm{N}-\mathrm{H}$ bond concentration will be set proportional to the $\mathrm{N}$ content:

$[\mathrm{N}-\mathrm{H}]=X_{\mathrm{NH}} \mathrm{N}$.

The coordination number of a $\mathrm{N}$ atom is 3 , while for a $\mathrm{N}-\mathrm{H}$ molecule it is 2 . So, the presence of the $\mathrm{N}-\mathrm{H}$ bonds will reduce the number of $\mathrm{Si}-\mathrm{N}$ bonds provided by the $\mathrm{N}$ atoms, and the factor 3 in Eq. (1) is accordingly reduced [12]

$2 x+\left(3-X_{\mathrm{NH}}\right) y=4$.

Fig. 1 shows a plot of $x$ as a function of y for both series of samples, measured by HI-ERDA and by AES. The dot line represents the relationship for stoichiometric films given by Eq. (1). The solid line is obtained by fitting the HI-ERDA values to Eq. (3). A perfect agreement is observed between the HI-ERDA experimental values and the theoretical behavior given by Eq. (4) to describe the presence of $\mathrm{N}-\mathrm{H}$ bonds. From the fit, the value for $X_{\mathrm{NH}}$ is obtained: $X_{\mathrm{NH}}=0.21 \pm 0.04$. This value is very similar to that reported in Ref. [12] using the same analysis. This value is lower than that given by Eq. (2), which is expected because $X_{\mathrm{NH}}$ takes into account bonded $\mathrm{H}$ only.

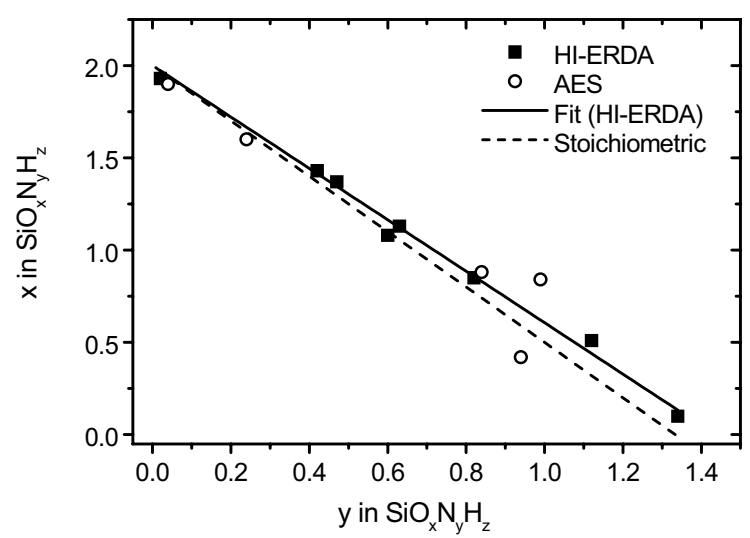

Fig. 1. Experimental relationship between $x=\mathrm{O} / \mathrm{Si}$ and $y=$ $\mathrm{N} / \mathrm{Si}$, measured by HI-ERDA and by AES, and theoretical relationship for stoichiometric films (dashed line).

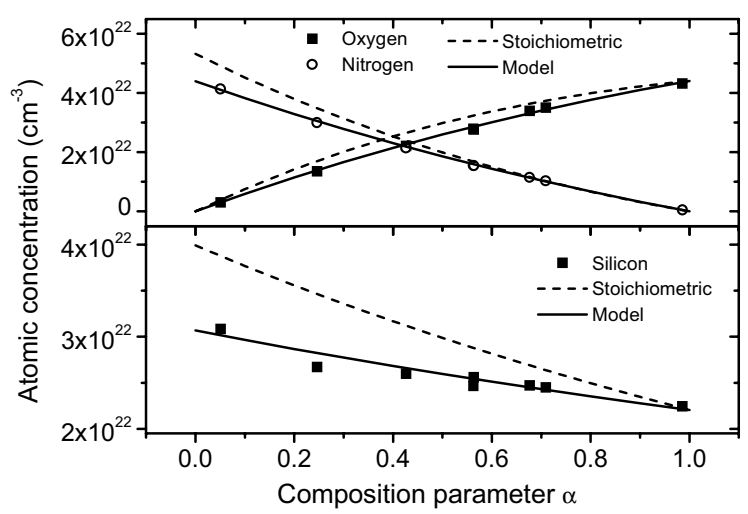

Fig. 2. Measured atomic concentration $\left(\operatorname{atoms} / \mathrm{cm}^{3}\right)$ of $\mathrm{O}, \mathrm{N}$ and $\mathrm{Si}$ as a function of film composition. The dashed lines represent the values for stoichiometric films. The solid lines are obtained by taking into account the incorporation of $\mathrm{H}$.

The results obtained by AES show the same trend, supporting the results obtained. The fit of these data to Eq. (4) provides the value: $X_{\mathrm{NH}(\mathrm{AES})}=0.20 \pm 0.22$. Due to the scatter of the AES measurements the uncertainty of this value is high. So, for the following discussion the HIERDA value will be used.

Fig. 2 shows the calculated atomic densities for $\mathrm{O}, \mathrm{N}$ and $\mathrm{Si}$ as a function of composition. The composition parameter $\alpha$ is defined as the ratio between the number of $\mathrm{Si}-\mathrm{O}$ bonds and the 
total number of $\mathrm{Si}-\mathrm{O}$ plus $\mathrm{Si}-\mathrm{N}$ bonds. Assuming $2 \mathrm{Si}-\mathrm{O}$ bonds per $\mathrm{O}$ atom and $3-X_{\mathrm{NH}} \mathrm{Si}-\mathrm{N}$ bonds per $\mathrm{N}$ atom:

$$
\begin{gathered}
\alpha=\frac{[\mathrm{Si}-\mathrm{O}]}{[\mathrm{Si}-\mathrm{O}]+[\mathrm{Si}-\mathrm{N}]}=\frac{2 x}{2 x+\left(3-\mathrm{X}_{\mathrm{NH}}\right) y} \\
\text { with } x=\frac{[\mathrm{O}]}{[\mathrm{Si}]} \text { and } y=\frac{[\mathrm{N}]}{[\mathrm{Si}]}
\end{gathered}
$$

For stoichiometric films $\left(X_{\mathrm{NH}}=0\right)$, this parameter determines the probability of the different constitutive tetrahedra [10]. Furthermore, according to Eq. (5), the $\mathrm{SiO}_{x} \mathrm{~N}_{y}$ formula for stoichiometric films can be written as $\left(\mathrm{SiO}_{2}\right)_{\alpha}\left(\mathrm{SiN}_{1.33}\right)_{1-\alpha}$. This formula does not imply separation of two phases. As previously stated, single-phase samples are obtained. However, the meaning of $\alpha$ as the fraction of oxide in the film is evidenced: $\alpha=0$ means silicon nitride, $\alpha=1$ means silicon oxide and $\alpha=0.5$ means the exact middle composition between oxide and nitride. So, this parameter $\alpha$ seems the most suitable one to represent composition.

For stoichiometric films, densities of 3.1 and $2.1 \mathrm{~g} / \mathrm{cm}^{3}$ are assumed for silicon nitride and silicon oxide, respectively [13]. For intermediate compositions the density is assumed to change linearly with the parameter $\alpha$. The atomic concentrations are obtained by taking into account Eq. (1) and the atomic weight of the different atoms. The stoichiometric concentrations are plotted in Fig. 2 as dashed lines.

The measured silicon and nitrogen concentrations are significantly lower than those expected for stoichiometric films, especially for samples close to silicon nitride composition. Concerning the oxygen concentration, a deviation from the stoichiometric behavior to lower values is also observed, but it is more significant for middle compositions.

These results can be explained by taking into account the effect of hydrogen. As it has been previously shown, for the samples under experiment, $\mathrm{H}$ is mainly incorporated into the films in the form of $\mathrm{N}-\mathrm{H}$ bonds. The proposed mechanism is that the $\mathrm{H}$ atoms replace $\mathrm{Si}$ atoms in the lattice, resulting in the observed decrease of the $\mathrm{Si}$ concentration with respect to the stoichiometric values. As the $\mathrm{N}$ and $\mathrm{O}$ atoms are bonded to $\mathrm{Si}$, the decrease in the Si concentration is responsible for the lower concentrations of both $\mathrm{N}$ and $\mathrm{O}$.

To check this hypothesis the following model has been developed.

The $\mathrm{H}$ is assumed to be incorporated as $\mathrm{N}-\mathrm{H}$ bonds. So, the formula for silicon oxynitride films $\mathrm{SiO}_{x} \mathrm{~N}_{y} \mathrm{H}_{z}$, containing $\mathrm{N}-\mathrm{H}$ bonds, will be written as

$$
\begin{aligned}
& \left(\mathrm{SiO}_{2}\right)_{\alpha}\left(\mathrm{SiN}_{m} \mathrm{H}_{n}\right)_{1-\alpha} \\
& \text { with } m=\frac{4}{3-X_{\mathrm{NH}}} \text { and } n=X_{\mathrm{NH}} m .
\end{aligned}
$$

The parameter $\alpha$ has the same meaning than for stoichiometric films. To calculate the $\mathrm{Si}, \mathrm{O}, \mathrm{N}$ and $\mathrm{H}$ concentrations an iterative process was performed. The stoichiometric values were used as start input. From the $\mathrm{N}$ concentration, the bonded $\mathrm{H}$ concentration is computed according to Eq. (6), using the value for $X_{\mathrm{NH}}$ obtained by fitting the HIERDA results to Eq. (3). For the simplest model, each bonded $\mathrm{H}$ atom is assumed to replace a $\mathrm{Si}$ atom. So the corrected $\mathrm{Si}$ concentration is obtained by subtracting the bonded $\mathrm{H}$ concentration from the Si stoichiometric concentration. The corrected $\mathrm{O}$ and $\mathrm{N}$ concentrations are then computed from Eq. (6). The process is repeated starting with the corrected $\mathrm{N}$ concentration until a self-consistent result is obtained.

Fig. 2 shows the results obtained by this model for $\mathrm{Si}, \mathrm{O}$ and $\mathrm{N}$ as solid lines. The results are in perfect agreement with the experimental values.

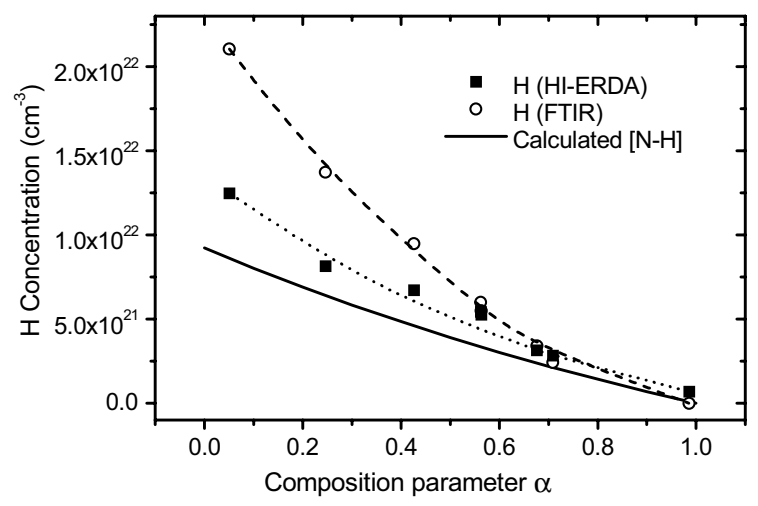

Fig. 3. H concentration measured by HI-ERDA and FTIR and calculated density of $\mathrm{N}-\mathrm{H}$ bonds as a function of composition. 
Fig. 3 shows the calculated $\mathrm{N}-\mathrm{H}$ concentration using the method described above, together with the experimental $\mathrm{H}$ concentration measured by HI-ERDA and the $\mathrm{H}$ calculated from the area of the FTIR N-H band, according to the method described by Lanford and Rand [14].

The HI-ERDA values are significantly higher than the calculated ones, especially for composition close to silicon nitride. The difference is attributed to the presence of non-bonded hydrogen, which is known to be present in silicon nitride films [11]. The low $\mathrm{H}$ concentration for silicon oxide films (around 1 at $\%$ ) and the observed relationship between $\mathrm{H}$ and $\mathrm{N}$ suggest that the incorporation of non-bonded $\mathrm{H}$ is also related to the $\mathrm{N}$ concentration. The replacement of $\mathrm{Si}$ atoms by $\mathrm{H}$ atoms described above may lead to the formation of microvoids in the films, where nonbonded hydrogen may be trapped. So, it is tentatively concluded that the presence of nonbonded hydrogen is linked to the presence of $\mathrm{N}-\mathrm{H}$ bonds.

The $\mathrm{H}$ concentration values obtained from FTIR deviate from those provided by HI-ERDA and also from the calculated $\mathrm{N}-\mathrm{H}$ concentration. The deviation is highest for silicon nitride films. These results suggest that the $\mathrm{H}$ concentration derived from FTIR is overestimated for samples near silicon nitride with respect to samples with higher $\mathrm{O}$ content. The results are obtained assuming the calibration factor given in Ref. [14] for silicon nitride, regardless of the actual composition of the film. The trend in Fig. 3 suggests that the factor should increase as composition approaches silicon oxide. A similar trend is reported in Ref. [12] when the $\mathrm{H}$ content calculated from FTIR is compared to the $\mathrm{N}-\mathrm{H}$ concentration obtained by Eq. (2). The ratio between the area of the FTIR $\mathrm{N}-\mathrm{H}$ band and the $\mathrm{H}$ content measured by nuclear reaction analysis (NRA) has also been reported to depend on the composition for silicon oxynitride. This dependence seemed to be related to specific bonding configurations present in the films [15]. The shift of the $\mathrm{N}-\mathrm{H}$ band maximum from 3330 to $3385 \mathrm{~cm}^{-1}$ as composition changes from nitride to oxide further supports the conclusion that the properties of the $\mathrm{N}-\mathrm{H}$ band are affected by composition.

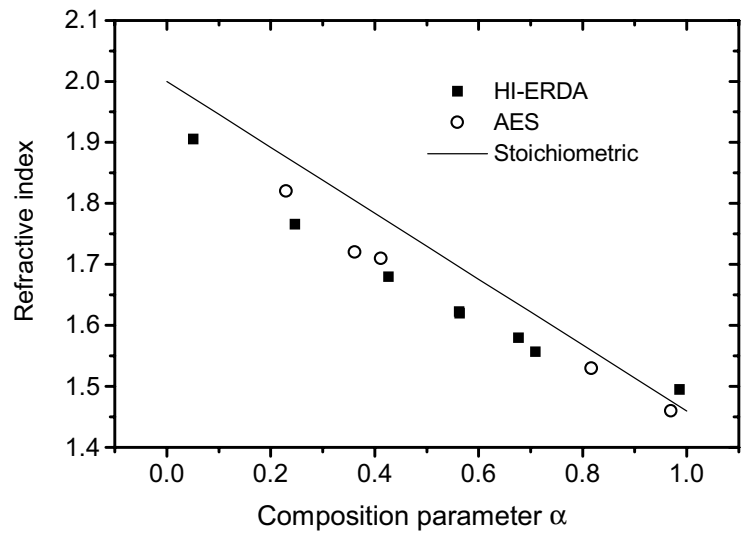

Fig. 4. Refractive index as a function of composition. The solid line represents the values for stoichiometric films.

Therefore, it is concluded that as composition changes from silicon nitride to silicon oxide, the calibration factor for the FTIR N-H band should increase, as shown by the trend observed in Fig. 3. So, the method to calculate $\mathrm{H}$ in silicon nitride proposed in Ref. [14], may not be fully reliable when applied to silicon oxynitride.

Finally, Fig. 4 shows the refractive index at $632.8 \mathrm{~nm}$ as a function of composition for samples characterized by HI-ERDA and by AES. The theoretical stoichiometric value is plotted as a solid line, assuming a refractive index value of 2 and 1.46 for silicon nitride and silicon oxide, respectively, and a linear dependence on the parameter $\alpha$. Although the expected linear behavior is observed, the experimental values are slightly lower than those for stoichiometric films, except for silicon oxide samples. It has been shown that the refractive index is related to the density of the films, with higher values of the refractive index for higher densities [4]. So, the results shown in Fig. 4 are perfectly consistent with the observed decrease in density with respect to stoichiometric silicon oxynitride due to the presence of hydrogen in these films.

\section{Conclusions}

Single-phase homogeneous silicon oxynitride films have been deposited within the full range of 
compositions between silicon nitride and silicon oxide. For the low $\mathrm{SiH}_{4}$ partial pressure used during deposition in this experiment, hydrogen is incorporated to the films in the form of $\mathrm{N}-\mathrm{H}$ bonds and as non-bonded hydrogen, while the $\mathrm{Si}-$ $\mathrm{H}$ bond concentration is below the detection limit. The hydrogen bonding to nitrogen replaces silicon atoms, resulting in a decrease of the silicon atomic concentration. As oxygen and nitrogen bond to silicon, the decrease of the silicon concentration results in a decrease of both oxygen and nitrogen concentrations with respect to stoichiometric samples. Furthermore, the substitution of silicon atoms by hydrogen atoms may result in the formation of voids, which are occupied by nonbonded hydrogen. Density calculations based in this substitution mechanism have been found to be in perfect agreement with experimental data.

The measured $\mathrm{H}$ content by HI-ERDA has been compared to the values obtained from the $\mathrm{N}-\mathrm{H}$ absorption IR band. The calibration factor of this band has been found to increase as composition approaches silicon oxide.

As a consequence of the incorporation of hydrogen, the films have a lower density and refractive index value with respect to hydrogenfree stoichiometric samples.

\section{Acknowledgements}

The authors acknowledge CAI de Implantación Iónica (UCM) for availability of deposition system and CAI de Espectroscopía (UCM) for availability of FTIR spectrometer. The work has been partially financed by the CICYT (Spain) under Contract No. TIC 98/0740. Technical support of G. Keiler is gratefully acknowledged.

\section{References}

[1] Ma Y, Lucovsky G. J Vac Sci Technol B 1994;12: 2504-10.

[2] Bulkin PV, Swart PL, Lacquet BM. J Non-Cryst Solids 1995;187:484-8.

[3] Chau TT, Mejia SR, Kao KC. J Vac Sci Technol B 1992;10:2170-8.

[4] Sassella A, Lucarno P, Borghesi A, Corni F, Rojas S, Zanotti L. J Non-Cryst Solids 1995; 187:395-402.

[5] Martínez FL, del Prado A, Mártil I, González-Díaz G, Bohne W, Fuhs W, Röhrich J, Selle B. Phys Rev B 2001;63:245

[6] Bohne W, Röhrich J, Röschert G. Nucl Instrum Methods B 1998;136-138:633.

[7] Bohne W, Fuhs W, Röhrich J, Selle B, González-Díaz G, Mártil I, Martínez FL, del Prado A. Surf Interface Anal 2000;30:534-7.

[8] del Prado A, Mártil I, Fernández M, González-Díaz G. Thin Solid Films 1999;343-344:437-40.

[9] del Prado A, Martínez FL, Mártil I, González-Díaz G, Fernández M. J Vac Sci Technol A 1999;17:1263-8.

[10] Eriksson TS, Granquist CG. J Appl Phys 1986;60: 2081-91.

[11] Martínez FL, del Prado A, Mártil I, Bravo D, López FJ. J Appl Phys 2000;88:2149-51.

[12] He LN, Inokuma T, Hasegawa S. Jpn J Appl Phys 1996;35:1503-8.

[13] Sze SM. Physics of semiconductor devices. New York: Wiley, 1981. p. 852.

[14] Lanford WA, Rand MJ. J Appl Phys 1978;49:2473-7.

[15] Denisse CMM, Janssen JFM, Habraken FHPM, van der Weg WF. Appl Phys Lett 1988;52:1308-10. 